\title{
USO DAS TERRAS E REMANESCENTES DO CERRADO DA MICRORREGIÃO DO VALE DO RIO DOS BOIS - GO: UMA ANÁLISE DAS MUDANÇAS NA PAISAGEM
}

\author{
Hellbia Samara Moreira de Carvalho Rodrigues ${ }^{(a)}$, Selma Simões de Castro ${ }^{(b)}$ \\ (a) Doutoranda em Geografia do Instituto de Estudos Sócio Ambientais/Universidade Federal de Goiás. \\ hellbiageografia1@gmail.com \\ (b) Docente do Instituto de Estudos Sócio Ambientais/Universidade Federal de Goiás. selma.castro@uol.com.br
}

Eixo: Uso e ocupação das terras e legislação ambiental

\begin{abstract}
Resumo
O presente artigo tem por objetivo analisar as mudanças na paisagem da microrregião do Vale do Rio dos Bois (MRVRB) situada no Sul do estado de Goiás com base num recorte temporal de 28 anos, através de uma análise comparativa do uso das terras e remanescentes do Cerrado de 1985 e 2013, mapeados com auxílio de ferramentas de sensoriamento remoto e geoprocessamento em ambiente Sistema de Informação Geográfica (SIG). O estudo permitiu observar uma grande mudança na estrutura dos remanescentes de Cerrado, os quais se tornaram fragmentados em consequência do aumento das áreas de uso antrópico associado à expansão da fronteira agrícola e expansão da cana-de-açúcar, respectivamente.
\end{abstract}

Palavras chave: Meio ambiente; Paisagem; Mudanças de uso do solo; Fragmentação.

\section{Introdução}

A Geografia utiliza-se constantemente de dados das ciências exatas, naturais e humanas, constituindo o seu corpo de estudos básicos e cujo papel é preencher a relação que existe entre os fenômenos físicos e humanos do planeta (MENDONÇA, 2001). Tratar das questões que relacionam sociedade e natureza é um desafio, visto que o ser humano possui necessidades básicas preenchidas com recursos desta extraídos, tornando-se seu maior agente transformador através, sobretudo, das mudanças de uso do solo.

Diversos conceitos fundamentam suas pesquisas que configuram como categorias de análise. $\mathrm{O}$ conceito paisagem é um dos principais e trabalhado com auxílio de diversos métodos, cujo histórico está ligado diretamente à própria história da Geografia como ciência. Nesta, Humboldt foi um dos principais teóricos do estudo da paisagem, abordando-a quanto à sua fisiologia, diante das diversidades de coisas no espaço e no tempo (VITTE, 2007). Como a paisagem é vista pelo observador, consequentemente está intimamente ligada às formas. 
"As utopias dos séculos XVIII e XIX - especialmente o socialismo e o marxismo - não levaram em consideração a dimensão ecológica em sua plenitude" (VESENTINE,1997, p. 19) e o crescimento econômico da sociedade, não levando em conta as degradações no meio ambiente, fez emergir a necessidade de repensar a problemática ecológica, principalmente diante do condicionamento da vida do ser humano no planeta, uma vez que este depende dos recursos naturais que são finitos.

No Brasil um pesquisador que contribuiu para o estudo das paisagens naturais foi Ab'Saber (2007), em cujos trabalhos se destaca o estudo dos diversos domínios naturais que compõem o território brasileiro, contribuindo enormemente para os avanços dos estudos geoambientais no Brasil, integrando em suas análises a Ecologia, Geologia, Biologia, Planejamento e até Política. A vegetação se traduz como importante aspecto na leitura da paisagem e é também uma variável importante que auxilia o reconhecimento de outras variáveis do ambiente, principalmente como tipos de solos, disponibilidade de recursos hídricos potenciais usos e clima. "Alexandre von Humboldt, foi o primeiro a reconhecer, por meio de observações sistemáticas, a importância da vegetação na característica da paisagem (SAUER, 2004, p.54)".

O Brasil possui em seu território 5 grandes biomas: Floresta Amazônica, Cerrado, Floresta Atlântica e de Araucária, a Caatinga o Pantanal e os Campos Sulinos (RIBEIRO et al., 2008) que se subdividem em ecorregiões (ROSS, 2006). Com o processo de intenso uso e ocupação induzido pela expansão da fronteira agrícola ao longo de sua história, o Brasil passou por grandes mudanças na cobertura do solo, com perda incalculável de biodiversidade, devido conversão agropecuária e fragmentação da cobertura natural, em particular na sua porção centro sul, onde o Bioma Cerrado era espacialmente expressivo, além da Mata Atlântica e da Floresta de Araucárias que praticamente desapareceram, enquanto do Cerrado ainda resta cerca da metade (PROBIO, 2002; INPE, 2015).

O Cerrado está localizado essencialmente no Planalto Central do Brasil e é o segundo maior bioma do país em área (KLINK; MACHADO, 2005), mesmo com a supressão de metade de sua área original desde a década de 1970, sendo apenas superado pela Floresta Amazônica (RIBEIRO; WALTER, 2008). Esse bioma ainda está passando por intensas transformações em suas paisagens associadas à expansão da fronteira agrícola, que se especializou em commodities voltadas, sobretudo, ao mercado internacional.

A importância de compreender a paisagem em um contexto histórico, comparativo se justifica, pois a paisagem não se cria de uma só vez, mas por acréscimo ou mesmo substituição (SANTOS, 2004). A paisagem da microrregião do Vale do Rio dos Bois (MRVRB) é representativa desse processo de mudanças do uso do solo e remanescentes do Cerrado desde a década de 1960 e, sobretudo 1970, que alterou notavelmente a região Sul goiano, onde se situa, em consequência da chamada Revolução Verde e 


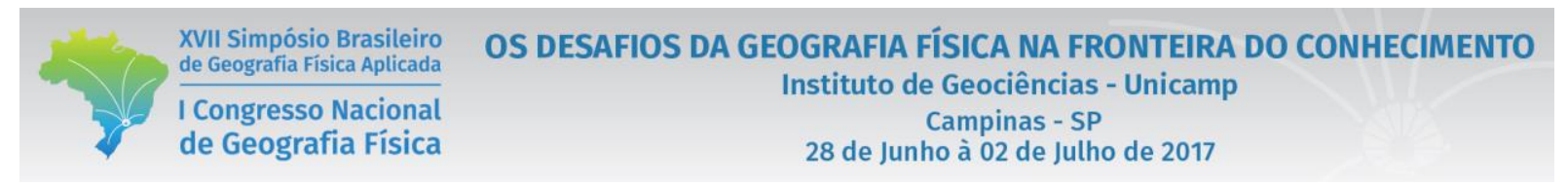

expansão da fronteira agrícola por incentivos do governo federal associados ao II Plano Nacional de Desenvolvimento (II PND), processo esse que continua de formas diferentes, mas mantendo a mesma estratégia de produção de commodities, como recentemente com a nova expansão canavieira (CASTRO et al., 2010).

O presente estudo objetiva analisar as transformações ocorridas na sua paisagem, de modo a classificar os diversos morfotipos de vegetação, em escala regional, e a compreender a dinâmica da apropriação do espaço por meio dos usos observados no intervalo de tempo adotado, estabelecidos para 1985 e 2013, por serem considerados o início da expansão da fronteira agrícola dos anos 1970 e a situação atual com a expansão da cana-de-açúcar, respectivamente. Além disso, o primeiro momento também se justifica pela intensificação do álcool e açúcar provenientes de recursos do PROÁLCOOL, além da ampla produção de commodities que já ocorria na área (RODRIGUES, 2015).

\section{Caracterização da Microrregião do Vale do Rio dos Bois}

A microrregião do Vale do Rio dos Bois (MRVRB) integra a mesorregião Sul do estado de Goiás, fazendo fronteira a leste com a microrregião do Meia Ponte e a Oeste com a microrregião do Sudoeste de Goiás. Está localizada à $16^{\circ} 35^{\prime} 25^{\prime} / 18^{\circ} 78^{\prime}, \mathrm{S}$ e $51^{\circ} 7,18^{\prime} / 51^{\circ} 7^{\prime} 5^{\prime} \mathrm{W}$, abrangendo aproximadamente 13.653,6 $\mathrm{Km}^{2}$ e contem treze municípios: Acreúna, Campestre de Goiás, Cezarina, Edealina, Edéia, Indiara, Jandaia, Palmeiras de Goiás, Palminópolis, Paraúna, São João da Paraúna, Turvelândia e Varjão (Figura 1).

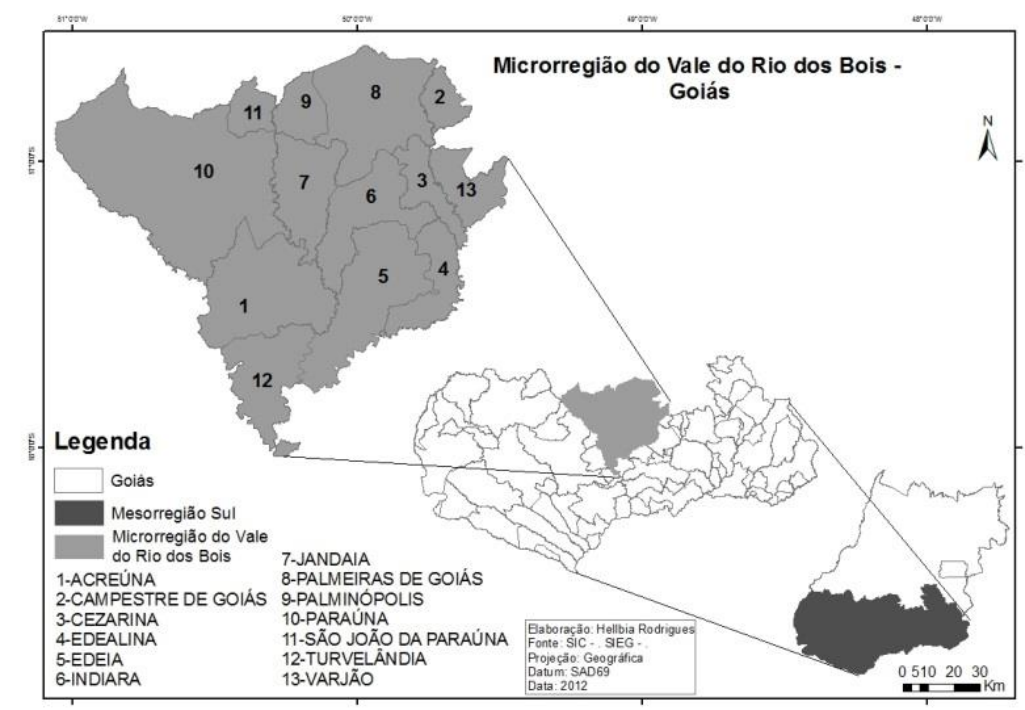

Figura 1. Localização e municípios da Microrregião do Vale do Rio dos Bois, estado de Goiás. Elaboração: Elaborado pelos autores, 2012. 


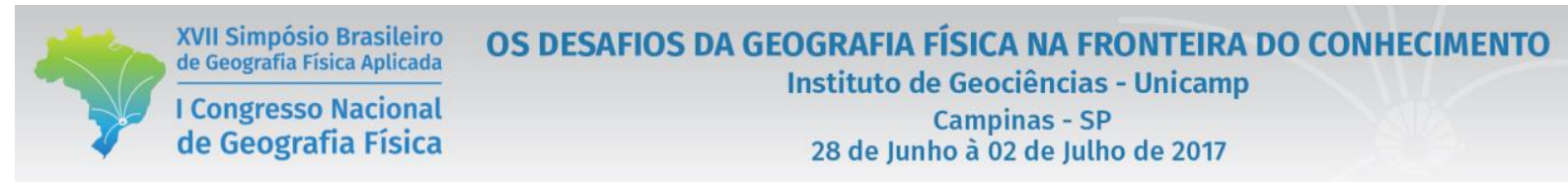

A MRVRB era dominada pelas fitofisionomias do Bioma Cerrado, que englobam as formações florestais, onde ocorrem espécies arbóreas de maior porte; as formações savânicas, que apresentam áreas com árvores, arbustos dispersos de menor porte que as anteriores, sobre coberturas de gramíneas; e as formações campestres, onde predominam espécies herbáceas e arbustivas (RIBEIRO \& WALTER, 2008).

Quanto aos solos predomina o Latossolo Vermelho distrófico (LVd) de caráter álico (EMBRAPA, 2013) ao Sul e Centro-Sul e de forma fragmentada no Sudeste, Noroeste e Oeste da MRVRB, como pode ser observado na figura 2. Trata-se de solo altamente favorável à agricultura, desde que corrigida sua acidez e aplicados adubos, por vezes irrigação na estação seca, dependendo da cultura praticada. Possui um relevo com predomínio de áreas planas a suave onduladas, relacionadas a aplainamentos de topos amplos associados aos solos espessos como o LVd, também favorece a atividade agrícola intensiva.

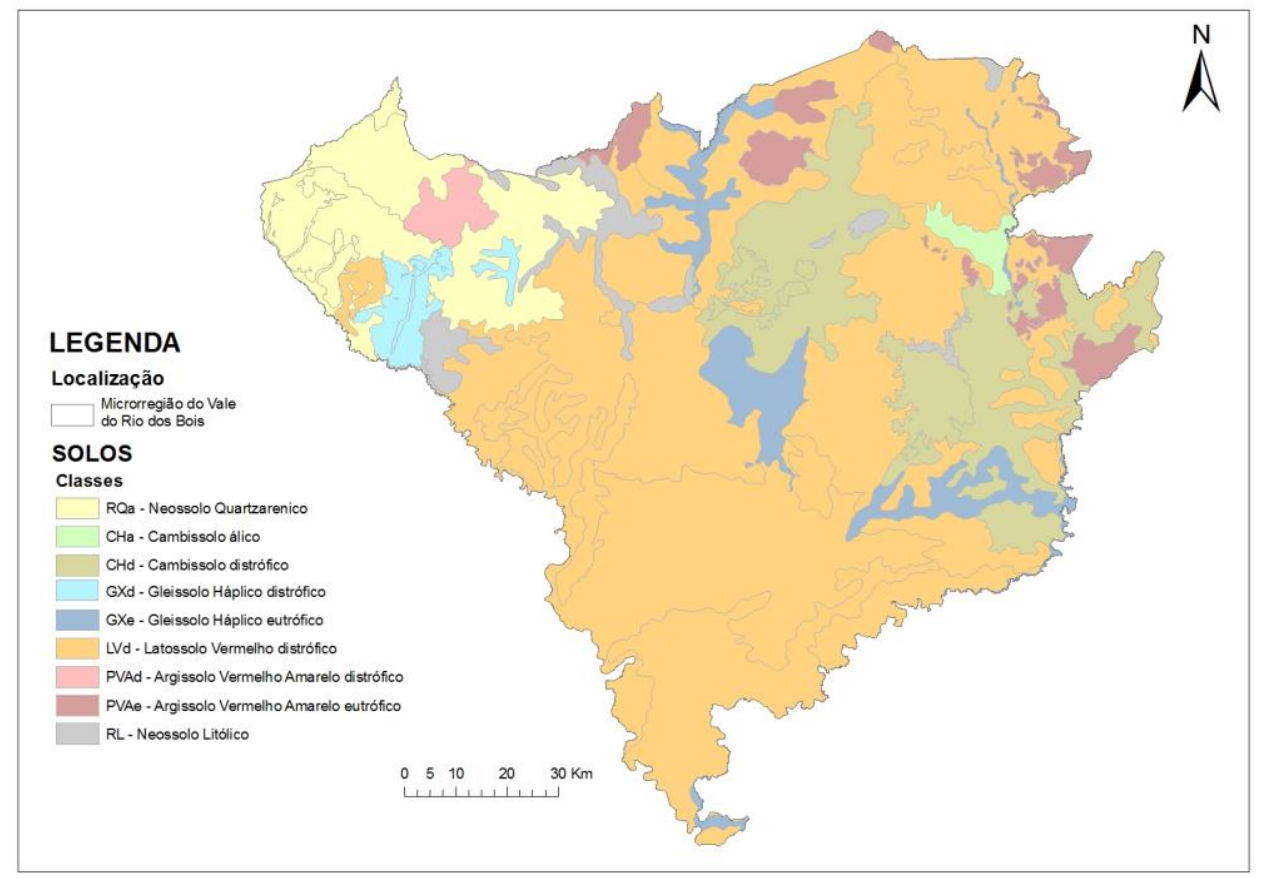

Figura 2. Solos da Microrregião do Vale do Rio dos Bois - GO.

Fonte: SIEG Elaboração: Rodrigues, 2014.

O clima da MRVRB é tropical subúmido, característico de áreas do Cerrado, marcado pela sucessão de duas estações bem distintas, uma quente e úmida (primavera-verão) e outra seca e fria (outono-inverno). A rede hidrográfica da MRVRB é densa e alguns de seus rios inclusive serviram para a sua delimitação regional (IBGE, 1950). A noroeste situam-se os rios Claro e São Domingos, afluentes do rio Araguaia, e no restante da microrregião ocorrem vários afluentes do rio Paraná (figura 3), todos de navegabilidade restrita a embarcações pequenas e períodos do ano. 

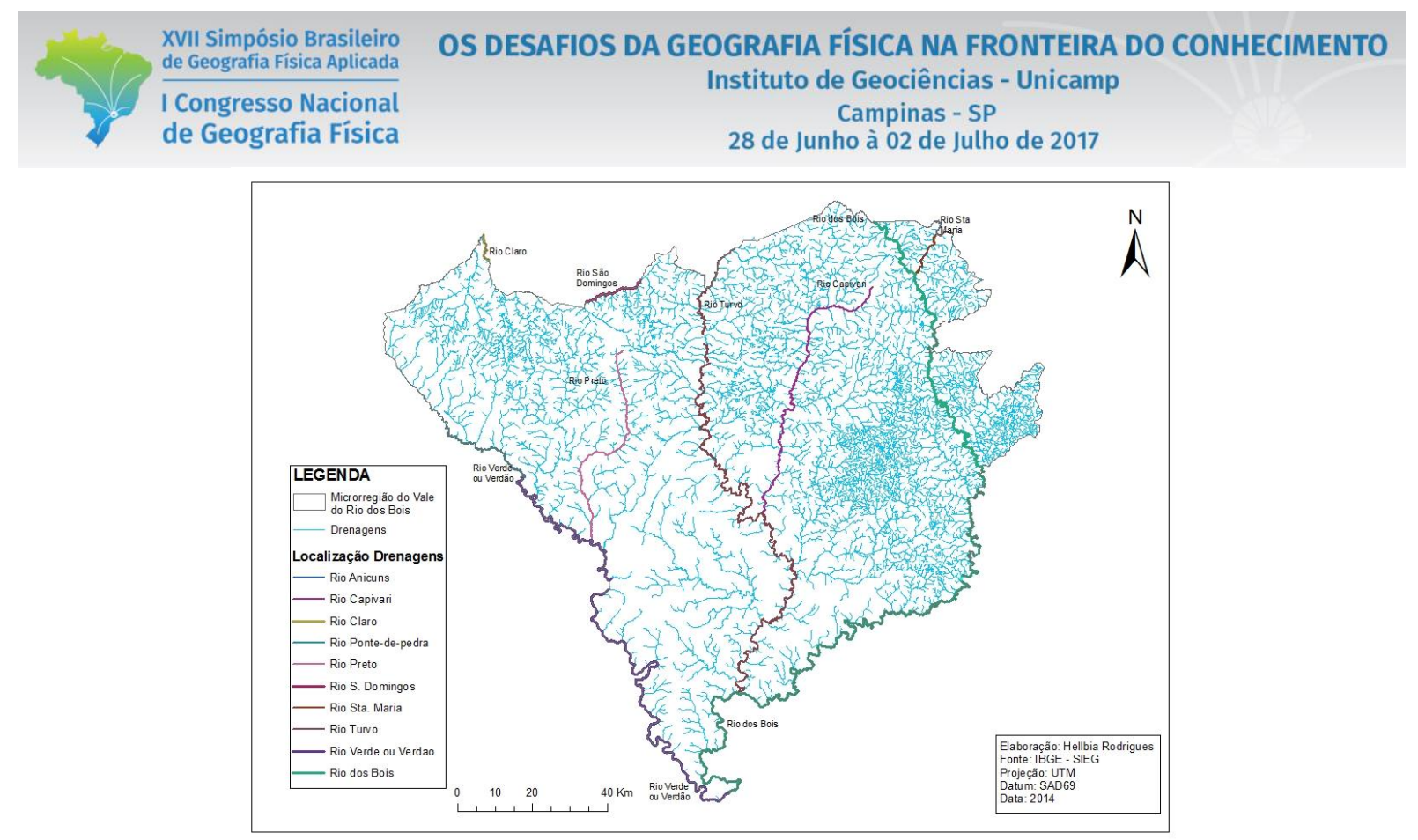

Figura 3. Rios da Microrregião do Vale do Rio dos Bois - GO. Elaboração: Rodrigues, 2014.

A MRVRB foi alvo da expansão da fronteira agrícola dos anos 1970, como exposto, promovendo uma intensificação no uso e ocupação das áreas através da conversão de áreas de remanescentes do Cerrado em áreas de pastagem e agricultura. Esta se voltou à produção de grãos, sobretudo soja, assim como a atuação de outros sendo uma das áreas preferenciais do PROÁLCOOL que vigorou de 1975 a 1979, produção essa que passa agora por nova expansão, desde 2004, quando o governo atua ao implementar uma segunda política favorável à expansão da cultura canavieira para a produção de biocombustíveis, conhecido como Plano Nacional de Agroenergia (PNA), que teve início com a emergência das questões ambientais e a poluição provocada por combustíveis fósseis, já possuindo em funcionamento 4 usinas. Mesmo assim, Miziara et al., (2008), numa análise multitemporal de 1940 à 1995, afirmam que a MRVRB mostrou pouca alteração no índice de ocupação pelas propriedades, evidenciando que seu processo de ocupação é mais antigo. Acrescente-se que a MRVRB ocupa posição privilegiada no estado de Goiás além de possuir ampla logística para escoamento de sua produção, o que favorece sua ocupação.

Diante do exposto, faz-se necessário incorporar a questão ambiental nos diversos âmbitos sociais da questão, por mais que a base econômica esteja na agropecuária, uma vez que é necessário espaço para produção, mas o ambiente necessita da vegetação para o equilíbrio físico do solo e dos recursos hídricos, e sua retirada indiscriminada pode acarretar impactos como erosão, assoreamento e perda incalculável de biodiversidade. Contudo, para Martins et al. (2004), a velocidade que as paisagens do Bioma Cerrado são transformadas diante das facilidades econômicas e das tecnologias modernas, dificulta até a possibilidade de estudar a biodiversidade e os mecanismos ecológicos dessas paisagens. 
Com o processo histórico relatado e a posição de pouca mudança tornou-se necessária a análise do uso das terras da MRVRB, para identificar e mapear as novas fisionomias da paisagem e quais os motores dessas transformações, de maneira a identificar e distinguir áreas onde a cobertura original reduziu mais substancialmente do que aquelas em que foi mais conservada, de modo a compreender e qual sua relação com a conversão agropecuária, no tempo.

\section{Metodologia}

Para elaboração da pesquisa inicialmente foi realizado um levantamento bibliográfico acerca da temática, no intuito de fundamentar os conceitos e métodos utilizados. Posteriormente, passou-se à obtenção de dados primários e secundários da pesquisa.

A base cartográfica foi elaborada com base em shapefiles compilados da base de dados do Sistema Estadual de Estatística e de Informações Geográficas do estado de Goiás - SIEG, cujos dados foram organizados no Software ARCGIS 9.3. Para elaboração do uso das terras e remanescentes do Cerrado foram compiladas imagens Landsat TM5, para o ano de 1985, trabalhadas na composição colorida tipo R(5), G(4), B(3) e, para o ano de 2013 foi compilada do satélite Landsat-8 OLI/TIRS, com composição colorida R(6), G(5), B(4). Observa-se que as imagens tanto de 1985 quanto de 2013 são do mês de junho, para a MRVRB são de órbita/ponto 222/72 e 223/72, ambas disponibilizadas gratuitamente pelo Instituto Nacional de Pesquisas Espaciais (INPE).

Após a compilação das imagens passou-se à fase de seu tratamento, procedendo-se com o registro da imagem (georreferenciamento) com base em imagens Geocover, um produto ortorretificado e registrado, procedimento esse realizado no Software ENVI. O processo de segmentação foi executado no SPRING, correspondendo ao método de Crescimento das regiões, no qual se divide a imagem em regiões que devem corresponder às áreas de interesse da aplicação. Por região, em uma imagem, entende-se um conjunto de pixels contíguos, que se espalham bidirecionalmente e que apresentam uniformidade. Após essa etapa, procedeu-se à classificação da imagem em classes distintas, no mesmo software, em que a última etapa foi desenvolvida no ARCGIS, a partir de classificação visual, onde cada polígono gerado em cada mapa foi classificado conforme a respectiva imagem ao fundo, para a classificação, sendo utilizada uma chave adaptada de Ribeiro e Walter (2008), conforme a tabela I. 
Tabela I: Chave de classificação

\begin{tabular}{|c|c|c|c|c|c|}
\hline \multirow{2}{*}{$\begin{array}{l}\text { Classes de } \\
\text { Formações }\end{array}$} & \multirow{2}{*}{$\begin{array}{c}\text { Classes de } \\
\text { Remanescentes } \\
\text { do Cerrado } \\
\text { e Usos }\end{array}$} & \multicolumn{4}{|c|}{ Características } \\
\hline & & Textura & Tonalidade & Porte & $\begin{array}{l}\text { Aspectos } \\
\text { Associados }\end{array}$ \\
\hline \multirow{3}{*}{$\begin{array}{l}\text { Formação } \\
\text { Campestre }\end{array}$} & Campo Limpo & $\begin{array}{c}\text { Lisa, } \\
\text { homogênea }\end{array}$ & $\begin{array}{l}\text { Arroxeado/ } \\
\text { Preto }\end{array}$ & Baixo & $\begin{array}{c}\text { Curso } \\
\text { d’água }\end{array}$ \\
\hline & Campo Sujo & $\begin{array}{l}\text { Fina com } \\
\text { grânulos }\end{array}$ & $\begin{array}{l}\text { Verde } \\
\text { médio/rosa }\end{array}$ & Baixo & $\begin{array}{c}\text { Formas } \\
\text { irregulares, } \\
\text { Árvores } \\
\text { Irregulares. }\end{array}$ \\
\hline & Cerrado Ralo & Grossa & Verde Claro & Baixo & $\begin{array}{l}\text { Árvores } \\
\text { isoladas }\end{array}$ \\
\hline \multirow{2}{*}{$\begin{array}{l}\text { Formação } \\
\text { Savânica }\end{array}$} & Cerrado Denso & Homogêneo & Verde Médio & $\begin{array}{l}\text { Médio/Al } \\
\text { to }\end{array}$ & $\begin{array}{l}\text { Formas } \\
\text { irregulares }\end{array}$ \\
\hline & Cerradão & Grossa & $\begin{array}{l}\text { Verde } \\
\text { Escuro }\end{array}$ & Alto & $\begin{array}{c}\text { Formas } \\
\text { irregulares }\end{array}$ \\
\hline $\begin{array}{l}\text { Formação } \\
\text { Florestal }\end{array}$ & Mata Ciliar & Homogêneo & Verde Médio & Alto & $\begin{array}{c}\text { Fundo de } \\
\text { Vale; Curso } \\
\text { d'água }\end{array}$ \\
\hline- & Agricultura & $\begin{array}{l}\text { Fina/ } \\
\text { Aveludada/ } \\
\text { Granular }\end{array}$ & $\begin{array}{l}\text { Rosa, Verde } \\
\text { Claro }\end{array}$ & Rasteiro & $\begin{array}{l}\text { Formas } \\
\text { Geométrica } \\
\text { s, Pivôs }\end{array}$ \\
\hline- & Pastagem & $\begin{array}{c}\text { Fina/ } \\
\text { Homogênea/ } \\
\text { Aveludada }\end{array}$ & $\begin{array}{c}\text { Clara com } \\
\text { algumas } \\
\text { variações }\end{array}$ & Baixo & $\begin{array}{c}\text { Geométrico } \\
\text { s/ Trilhas/ } \\
\text { Áreas } \\
\text { Isoladas/ } \\
\text { Áreas } \\
\text { Rebaixadas } \\
\text { e Fundos de } \\
\text { Vale }\end{array}$ \\
\hline- & Área Urbana & Grossa & $\begin{array}{c}\text { Cinza } \\
\text { Claro/Médio }\end{array}$ & & $\begin{array}{c}\text { Formas } \\
\text { Geométrica } \\
\text { s/ } \\
\text { Arruamento } \\
\mathrm{s}\end{array}$ \\
\hline
\end{tabular}

Fonte: Elaborados pelos autores, 2013; adaptado de Ribeiro e Walter (2008).

\section{Análise Comparada dos Remanescentes e usos das terras da MRVRB}

A análise da paisagem da MRVRB propiciou o reconhecimento da vegetação remanescente presente em 1985 e em 2013, bem como dos demais usos. Constatou-se predomínio das áreas de agricultura e pastagem, fato compatível com a economia do estado de Goiás, e em particular, da sua mesorregião Sul, tida como referência na produção de grãos e carne e, mais recentemente, de cana-de-açúcar. 


$\begin{array}{lc}\begin{array}{l}\text { XVII Simpósio Brasileiro } \\ \text { de Geografia Fisica Aplicada }\end{array} & \text { OS DESAFIOS DA GEOGRAFIA FÍSICA NA FRONTEIRA DO CONHECIMENTO } \\ \begin{array}{l}\text { I Congresso Nacional } \\ \text { de Geografia Física }\end{array} & 28 \text { de Junho à } 02 \text { de Julho de } 2017\end{array}$

Ao analisar o ano de 1985 a classe de agricultura já representava 41,41\% da área, e em 2013 alcançava $52 \%$ da área. Já na classe de pastagem a área segue com pouca variação de 21,35\% em 1985 para 22,07\% em 2013 (Figura 4 e 5, e Tabela II).

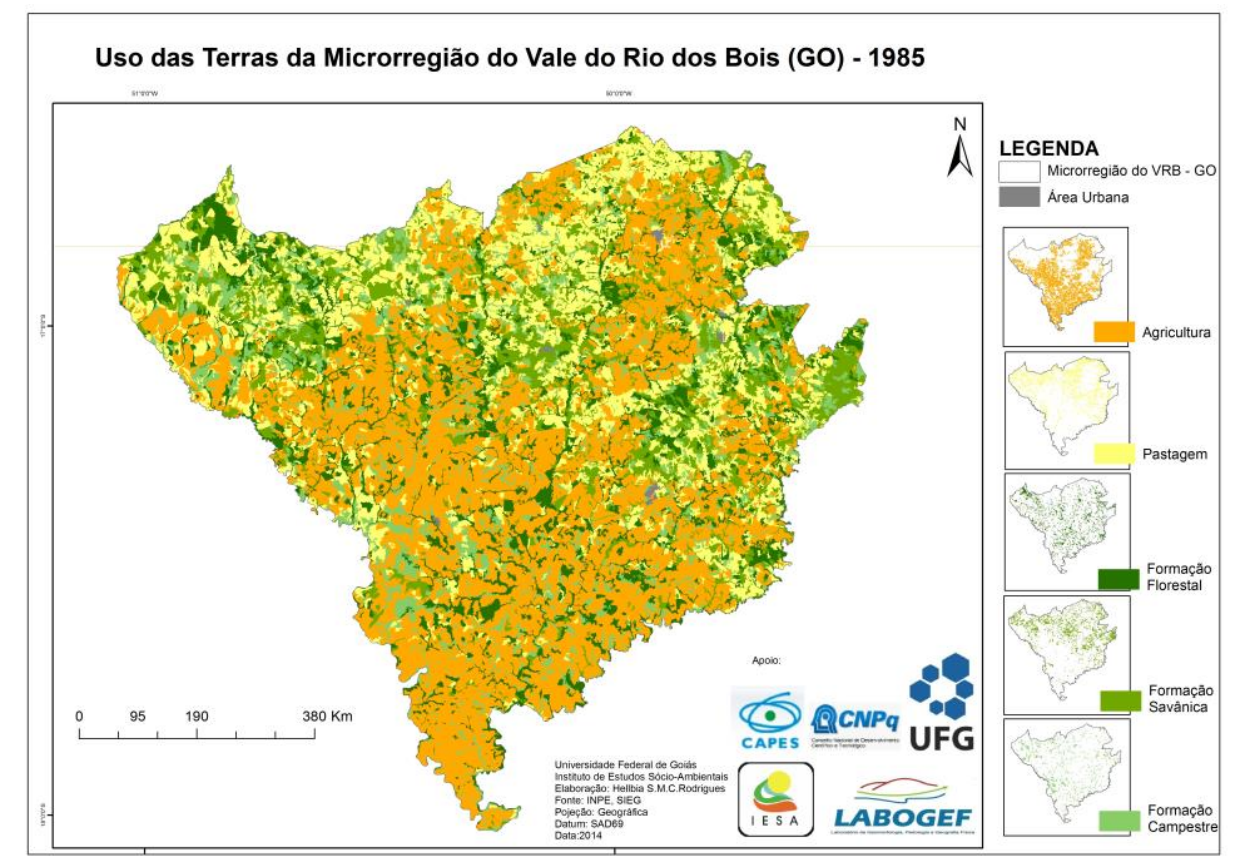

Figura 4. Uso das terras da Microrregião do Vale do Rio dos Bois 1985. Elaboração: Rodrigues, 2014.

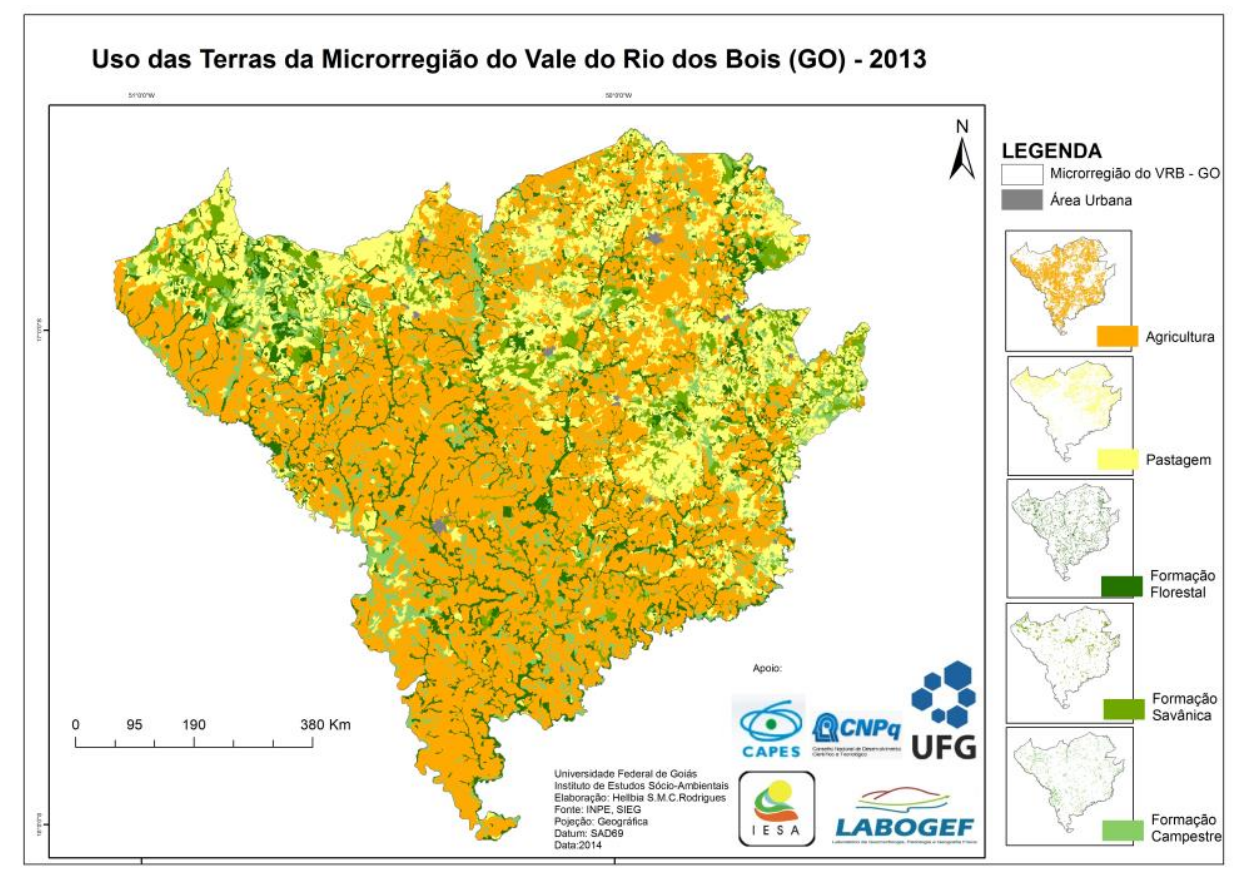

Figura 5. Uso das Terras da Microrregião do Vale do Rio dos Bois 2013. 


\section{OS DESAFIOS DA GEOGRAFIA FÍSICA NA FRONTEIRA DO CONHECIMENTO \\ Instituto de Geociências - Unicamp \\ Campinas - SP \\ 28 de Junho à 02 de Julho de 2017}

Elaboração: Rodrigues, 2014.

Tabela II. Comparação do Uso das terras entre os anos de 1985 e 2013

\begin{tabular}{l|rrrr}
\hline \multirow{2}{*}{ Classe } & \multicolumn{1}{|c}{$\mathbf{1 9 8 5}$} & \multicolumn{2}{c}{$\mathbf{2 0 1 3}$} \\
\cline { 2 - 5 } & \multicolumn{1}{c}{ Ha } & \% & Ha & \% \\
\hline Área Urbana & 2877,8 & 0,21 & 3631,5 & 0,2 \\
Agricultura & 562830,9 & 41,4 & 706767,5 & 52 \\
Pastagem & 290159,4 & 21,3 & 299996,9 & 22 \\
Formação Florestal & 175237,6 & 12,8 & 149226,9 & 10 \\
Formação Savânica & 200132,8 & 14,7 & 88574,7 & 6,5 \\
Formação Campestre & 127579,6 & 9,38 & 110816,6 & 8,1 \\
Total & 1359014 & 100 & 1359014 & 100 \\
\hline
\end{tabular}

As áreas de agricultura na MRVRB predominam sobre os melhores solos, como na porção sul onde predominam os Latossolos, sobretudo o $\mathrm{LVd}$, em relevos que variam de plano a suave ondulado, associado à uma Superfície Regional de Aplainamento (Chapada) (LATRUBESSE \& CARVALHO, 2006), além de contarem com grande disponibilidade hídrica, proveniente do rio dos Bois e do rio Verdão. As pastagens ocorrem em áreas onde o relevo é mais movimentado, na porção norte, onde ainda ocorrem manchas de vegetação natural, mas que estão sujeitas à pressão de ocupação antrópica, como na porção norte-noroeste, onde predominam formações savânicas sobre Neossolos Quartzarênicos e Litólicos.

A porção norte apresenta um relevo movimentado, com ocorrência de Neossolos Litólicos, Cambissolos e Argissolos, que necessitam de atenção na intervenção, devido sua erodibilidade, pelo que demandam respeito às fragilidades da área e à baixa ou regular aptidão agrícola, em que o uso inadequado pode promover impactos irreversíveis. Um dos impactos que já antecede a data do presente mapeamento que é o de fragmentação da cobertura natural, o qual reduz a riqueza de espécies e interfere na dinâmica do(s) ecossistema(s).

O mapeamento realizado permitiu constatar que os remanescentes do Cerrado em 1985 correspondiam a 37\% da área total da MRVRB e em 2013 a 25,65\%, revelando desmatamento e expansão da conversão agropecuária de cerca de 10\% em área. Em 1985 destacava-se a formação savânica que representava 14,72\%, seguindo-se a formação florestal com 12,89\% e a formação campestre com 9,38\% da área total. No ano de 2013 ainda se destaca a formação florestal, no entanto, já com uma redução para 10,98\% da sua área, ressaltando-se que se retringe aos fragmentos próximos às drenagens (matas ciliares/galeria). Seguese a formação savânica que reduziu também a cerca da metade no período restando 6,5\% da área anterior e 
por último a formação campestre, com $8,15 \%$ que também expressa redução, embora menor. Como pode ser observado nas figuras 4 e 5 , na porção norte estes fragmentos predominam na paisagem, mas passaram ser ocupados por áreas de pastagens no ano de 2013.

A retirada da cobertura vegetal pode gerar impactos ambientais importantes. De acordo com Troll, "A vegetação situa-se no centro do ecossistema, já que determina com sua existência o microclima, influencia na erosão do solo por meio da deposição de seus restos, regula a estrutura hídrica (...)" (TROLL, 1996, p.6).

A partir dos dados expostos é possível afirmar que a paisagem na MRVRB, quanto aos seus remanescentes de Cerrado, encontra-se bem fragmentada, tendo aumentado a fragmentação de 1985 para 2013. As mudanças que ocorreram na cobertura do solo reconfiguraram a paisagem microrregional. Assim, esse processo associou-se à expansão da fronteira agrícola, como esperado, a qual avançou sobre os remanescentes florestais e savânicos, em princípio sempre associados aos melhores solos da microrregião, ou de melhor aptidão agrícola.

A supressão da cobertura e sua fragmentação em remanescentes induziram mudanças nas paisagens da MRVRB, em especial nas partes antes florestadas e de vegetação savânica, as mais afetadas pela conversão agropecuária, correspondendo juntas a mais da metade da microrregião, concentrando-se na sua porção centro-sul. Além da perda da biodiversidade, os impactos resultantes podem ser a erosão no solo e também o aumento do déficit hídrico, diante das altas demandas agrícolas e, por fim, também a mudança do clima em microescala. A fragmentação ainda pode provocar o isolamento de comunidades biológicas e espécies, o que, segundo Martins et al. (2004), acarretaria a diminuição do fluxo gênico, podendo ocorrer progressiva decadência genética de comunidades.

A análise da MRVRB de 1985 e 2013 revela como a dinâmica de uso e ocupação das terras avançou e continua avançando rapidamente sobre áreas com remanescentes de Cerrado por desmatamento e conversão agropecuária. Constatou-se também que as áreas de pastagem pré-existentes foram sendo ocupadas por atividades agrícolas e as novas, por sua vez, cederam áreas de remanescentes que foram convertidos em pastagens, revelando a sucessão remanescente - pastagem - agricultura que se reproduz no tempo (CASTRO et al., 2010; ABDALA \& CASTRO, 2010). Tal processo corrobora as interpretações correntes sobre a apropriação do Cerrado como também ressalta o fato de que, os avanços em pesquisas e políticas governamentais não são igualmente rápidos como a dinâmica do crescimento econômico e apropriação do espaço, uma vez que as mudanças ocorrem num curto tempo e a natureza não consegue recompor a cobertura nesse ritmo imposto pelo ser humano. 


\section{Considerações Finais}

O uso das terras e cobertura em 1985 já era em grande parte agropecuário, sobretudo na porção sul, onde dominam relevos e solos mais aptos à agricultura, quando a vegetação era destinada a áreas de preservação permanente (APP) e supostamente de reserva legal (RL). Em 2013 essas áreas vegetadas sofreram uma pressão ainda maior, pois que as áreas agrícolas e pastos aumentaram, observando que as áreas de pastagem pré-existentes foram sendo ocupadas por atividades agrícolas e as novas, por sua vez, cederam áreas de remanescentes que foram convertidos em pastagens, revelando a sucessão remanescente - pastagem - agricultura que se reproduz no tempo.

Convém observar que a mudança da paisagem ocorre em diversos níveis organizacionais, impulsionada por diversos fatores, sendo necessário compreender a dinâmica dessa transformação e seus impactos, principalmente por ser o sistema econômico o principal propulsor dessas mudanças. Vitte (2007) alerta sobre o distanciamento do ser humano da natureza e a confusão feita diante de processos considerados naturais, por meio do pensamento científico, vendo como natureza o que na verdade é desnaturalizada. A MRVRB representa bem essa ideia.

Os estudos de detalhe sobre a ocupação da MRVRB podem vir a auxiliar a elaboração de políticas públicas, que promovam o melhor uso e manejo das terras bem como a intensificação de fiscalização para impedir abusos, em particular sobre a fragmentação dos remanescentes da área, diante de dinâmica intensa de uso, principalmente quanto aos efeitos da nova lei 12.651 de 2012, que mudou substancialmente o antigo Código Florestal.

\section{Agradecimentos}

Ao Conselho Nacional de Pesquisa - CNPq, pela bolsa de mestrado, assim como ao Laboratório de Geomorfologia, Pedologia e Geografia Física do Instituto de Estudos Socio-Ambientais da Universidade Federal de Goiás que possibilitou o uso de instalações e recursos tecnológicos para o desenvolvimento da pesquisa.

\section{Bibliografia}

ABDALA, K.; CASTRO, S.S. Dinâmica de uso do solo da expansão sucroalcooleira na Microrregião Meia Ponte, estado de Goiás, Brasil. In VI SEM. LATINO-AMERICANO DE GEOGRAFIA FÍSICA, Portugal, maio de 2010. Anais. Disponível em http://www.uc.pt/fluc/cegot/VISLAGF/actas/tema3/klaus. Acesso em 02 de julho de 2010.

AB`SABER, A. N. Os domínios de natureza no Brasil: potencialidades paisagísticas. $4^{\text {a }}$ ed. São Paulo: Ateliê Editorial, 2007. 


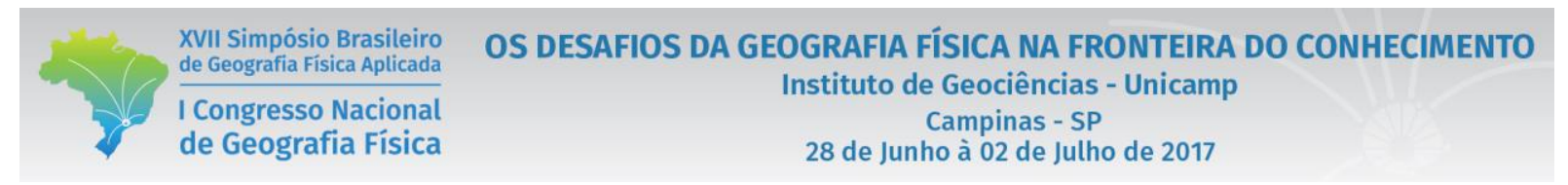

CASTRO, S.S. de; ABDALA, K; SILVA, A; BORGES, V. A expansão da cana-de-açúcar no cerrado e no estado de Goiás: Elementos para uma análise espacial do processo. Boletim Goiano de Geografia. Goiânia, 2010.

EMBRAPA. Sistema Brasileiro de Classificação de solos. Rio de Janeiro: Embrapa Solos, 2013.

INPE - Instituto Espacial de Pesquisas Espaciais TerraClass Cerrado, Projeto TerraClass Cerrado Mapeamento do Uso e Cobertura Vegetal do Cerrado - 2015.

INPE - Instituto Espacial de Pesquisas Espaciais. Disponível em http://www.dsr.inpe.br/laf/canasat/ > acesso em 10 jan. 2013.

KLINK, C. A.; MACHADO, R.B. Conservation of the Brazilian Cerrado. Conservation Biology.v. 19 , 707 -713. 2005.

LATRUBESSE, E. M.; CARVALHO, T. M. Geomorfologia do Estado de Goiás e Distrito Federal. Secretaria de Industria e Comércio. Superintendência de Geologia e Mineração. Goiás, 2006.

MARTINS, É. da S.; REATTO, A.; JUNIIOR, O. A. de C. Ecologia da Paisagem: conceitos e aplicações potenciais no Brasil. Planaltina, DF: Embrapa Cerrados, 2004. 35p. -(Documentos Embrapa Cerrados, ISSN 15175111; 121).

MENDONÇA, Francisco. Geografia Física: ciência humana? . 7a ed. São Paulo: Contexto, 2001.

MIZIARA, F.; FERREIRA, N C. Expansão da fronteira agrícola e evolução da ocupação e uso do espaço no Estado de Goiás - subsídios à política ambiental. In: GUIMARÃES, L. F. (Org.) A encruzilhada socioambiental: biodiversidade, economia e sustentabilidade no cerrado. Goiânia: Editora da UFG, 2008.

PROBIO - Projeto de Conservação e Utilização Sustentável da Diversidade Biológica Brasileira. Relatório de atividades. Brasília: Ministério do Meio Ambiente, 2002.

RIBEIRO, J. F.; WALTER, B. T. As Principais Fitofisionomias do Bioma Cerrado. In: SANO, S. M.; ALMEIDA, S. P. de.; RIBEIRO, J. F. R. (Ed.). Cerrado: Ecologia e Flora. Brasília, DF: Embrapa Informações Tecnológicas; Planaltina, DF: Embrapa Cerrados, 2008. v. 1, P. 151-212.

RODRIGUES, H. S. M. de C.; CASTRO, S. S. de. Avaliação da expansão recente da cana-de-açúcar em solos frágeis na microrregião do Vale do Rio dos Bois-GO. In: CASTRO, S. S. de; HERNANI, L. C. e (Org). Solos Frágeis - Caracterização, Manejo e Sustentabilidade Brasília, DF: Embrapa, 2015.

ROSS, J. L. S. Ecogeografia do Brasil: Subsídios para planejamento ambiental. $1^{a}$ ed. Oficina de Textos, São Paulo, 2006.

SANTOS, M. A natureza do espaço: técnica e tempo, razão e emoção. 4. ed. São Paulo: EDUSP, 2004.

SAUER, C. O. A Morfologia da Paisagem. In: Paisagem, tempo e cultura - (Org) CORRÊA, R. L.; ROSENDAHL, Z. $2^{\text {a }}$ ed. Rio de Janeiro: UERJ, 2004.

TROLL, C. Paisagem Geográfica e sua Investigação. In: Espaço e Cultura. N2. Rio de Janeiro: UERJ, NEPEC, 1996.

VESENTINI, J.W. Geografia, natureza e sociedade. $4^{\text {a }}$ ed. São Paulo: Contexto, 1997.

VITTE, A. C. Da Natureza da Metafísica à Gênese da Geografia Física Moderna. In: VITTE, A. C. e (Org). Contribuições à história e a epistemologia da geografia. Rio de Janeiro: Bertrand Brasil, 2007. 294p. 